\title{
PERANCANGAN PEMBANGKIT LISTRIK TANPA BBM UNTUK PENERANGAN KAPAL NELAYAN DAN RUMAH PENDUDUK SERTA MENINGKATKAN KESEJAHTERAAN EKONOMI KELOMPOK PEDAGANG GORENGAN DI KELURAHAN MANGGAR
}

\author{
Andi Sri Irtawaty ${ }^{1}$, Lilik Damayanti ${ }^{2}$, Subur Mulyanto ${ }^{3}$ \\ ${ }^{1,2,3}$ Politeknik Negeri Balikpapan \\ andi.sri@poltekba.ac.id
}

\begin{abstract}
Abstrak
Abstrak Energi listrik merupakan kebutuhan primer dalam kehidupan manusia modern. Seiring bertambahnya jumlah penduduk, maka kebutuhan listrik juga semakin bertambah. Dalam kondisi tertentu, terutama bagi kelompok nelayan dan pedagang gorengan, terutama saat di malam hari, tentunya membutuhkan perangkat tambahan yang memerlukan bahan bakar minyak (bbm) sebagai sumber energy penerangannya. Berdasarkan survey lapangan, dalam sebulan nelayan menggunakan solar sebanyak 20 liter x 30 hari x Rp 6000,$=$ Rp 3.600.000,- untuk menggerakkan mesin genset. Oleh karena itu, tim PkM Politeknik Negeri Balikpapan berinovasi merancang sebuah pembangkit listrik tanpa bbm dengan kapasitas 300 watt dan 1000 watt yang dirakit dari aki 12 volt 5A untuk inverter 300 watt dan aki 12 volt $8 \mathrm{~A}$ untuk inverter 1000 watt. Perancangan alat tersebut disajikan dalam bentuk praktek pada kegiatan $\mathrm{PkM}$ selama 3 hari kerja (luring 2 hari dan daring 1 hari) di Kelurahan Manggar yang dihadiri 20 peserta dari kalangan nelayan dan pedagang gorengan. Hasil kuisioner peserta, alat tersebut sangat bermanfaat, setidaknya mengurangi penggunaan solar genset menjadi Rp 0,- (khusus untuk keperluan penerangan di malam hari).
\end{abstract}

Kata Kunci : pembangkit listrik tanpa bbm, hemat energy, bbm, penerangan, kelurahan manggar.

\section{PENDAHULUAN}

Hampir semua aspek kehidupan memerlukan energi listrik sebagai penggerak utama. Pada umumnya, sumber energy listrik manusia selain dari PLN juga dari mesin genset yang rata-rata mnenggunakan bahan bakar minyak. Faktor meningkatnya bahan bakar minyak dan semakin bertambahnya kebutuhan penduduk akan penggunaan listrik mengakibatkan timbulnya masalah lingkungan dan ekonomi terutama bagi masyarakat ekonomi menengah ke bawah. (Juwito, 2012).

Berdasarkan latar belakang tersebut, maka perlu adanya solusi yang tepat dalam mengatasi kesulitan perekonomian tersebut.
Semakin bertambahnya jumlah manusia, tentunya diiringi dengan pertambahan kebutuhan listrik yang selayaknya, sehingga perlu dirancang sebuah pembangkit listrik tanpa menggunakan bahan bakar minyak (bbm), agar penggunaan konsumsi listrik bagi masyarakat menengah ke bawah dapat lebih hemat.

Mitra PkM yang ditunjuk dalam kegiatan PkM di tahun 2020 adalah masyarakat Kelurahan Manggar yang bermata pengcaharian sebagai nelayan dan pedagang gorengan untuk keperluan penerangan di malam hari diperlukan pembangkit listrik tanpa bbm kapasitas 300 watt dan untuk keperluan lainnya (menggerakkan mesin air dan kulkas menggunakan pembangkit listrik tanpa bbm untuk kapasitas 1000 watt).

$$
\text { Teknologi Tepat Guna }
$$


Tujuan akhir dari kegiatan PkM tersebut adalah menekan biaya pembayaran listrik PLN sehingga dapat meningkatkan taraf perekonomian bagi masyarakat Kelurahan Manggar. Berdasarkan wawancara dengan nelayan, sebelum menggunakan pembangkit listrik tanpa bbm, mereka menggunakan solar untuk penerangan di malam hari sebesar Rp 108.000,-/ bulan menjadi Rp 0,setelah menggunakan pembangkit listrik tersebut.

\section{METODE}

Metode pelaksanaan kegiatan PkM ini, meliputi tahapan-tahapan sebagai berikut:

a. Tahapan 1 (persiapan)

Tahap ini meliputi survey lokasi, yang menjadi sasaran mitra yaitu warga nelayan dan pedagang gorengan di Kelurahan Manggar, Kecamatan Balikpapan Timur, Kota Balikpapan. Permasalahannya yaitu melambungnya harga bahan bakar sementara tingkat perekonomian masyarakat masih tergolong menengah ke bawah, sehingga tim pengusul kegiatan PkM memberikan solusi yang tepat berupa inovasi teknologi berupa pembangkit listrik tanpa bbm untuk keperluan penerangan kapal nelayan dan rumah penduduk serta untuk mesin air dan kulkas bagi pedagang gorengan.

b. Tahapan II (perancangan pembangkit listrik tanpa bbm).

Pada tahap ini, tim PkM DPRM 2020 telah menyiapkan 20 unit komponen lengkap untuk mitra (19 unit berkapasitas 300 watt dan 1 unit berkapasitas 1000 watt sebanyak 1 unit). Gambar 1 mendeskripsikan diagram alir / flowchart proses perancangan pembangkit listrik tanpa bbm hingga tahap pengujiannya.

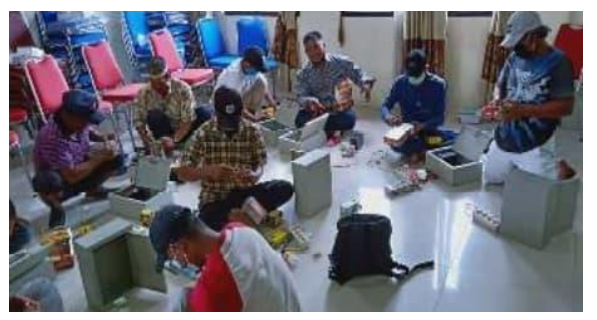

Gambar 1. Kegiatan praktek di hari pertama PkM

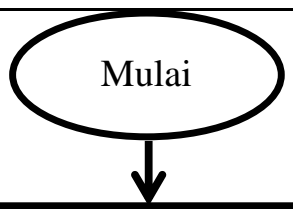

Inisialisasi input :

Aki 12 volt 5 Ah battery, inverter 300 watt, charger aki 2A, aki 12 volt

$8 \mathrm{Ah}$, inverter 1000 watt charger aki 4A charger, stop kontak, kabel

NYY $0.5 \mathrm{~mm}$

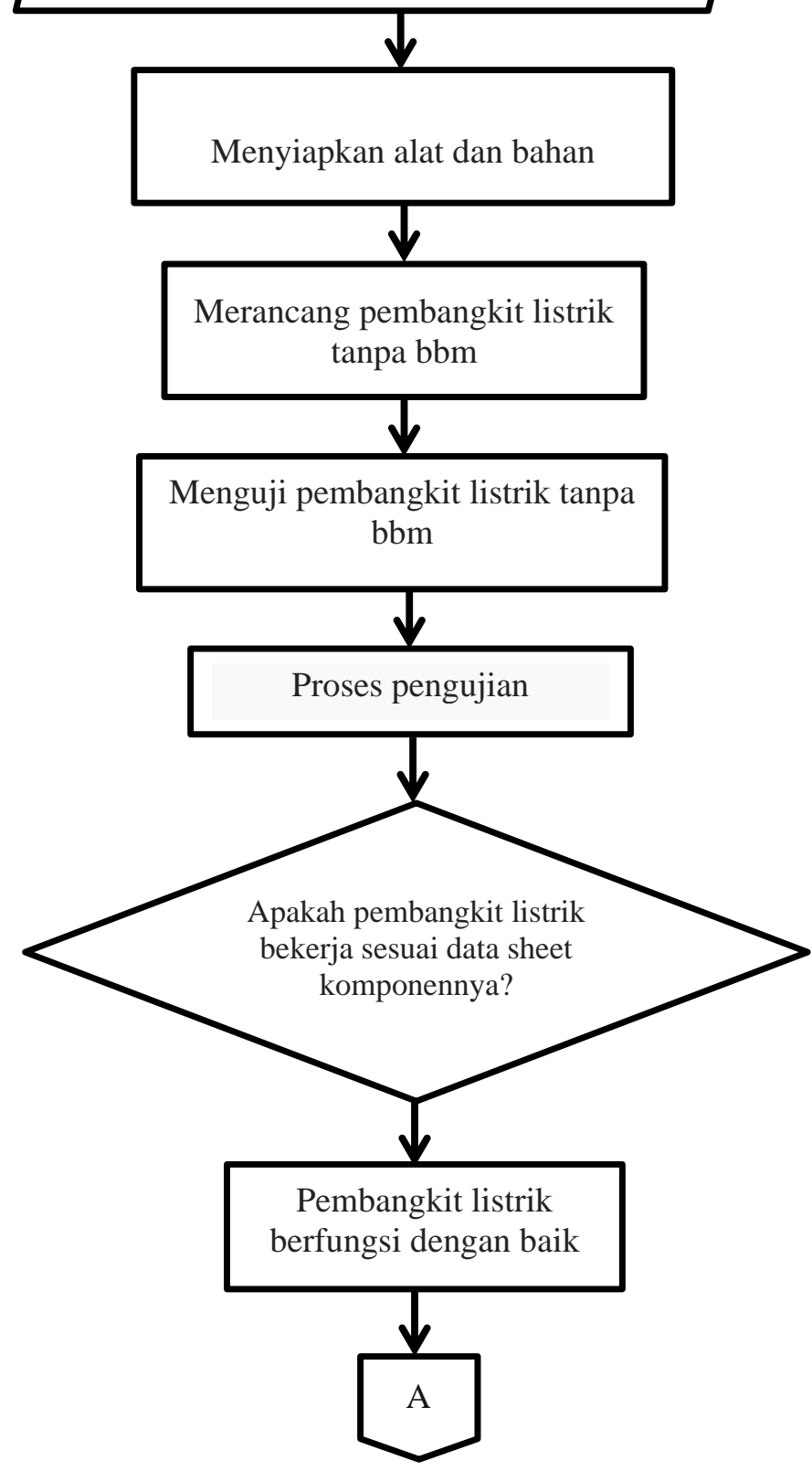

Teknologi Tepat Guna 


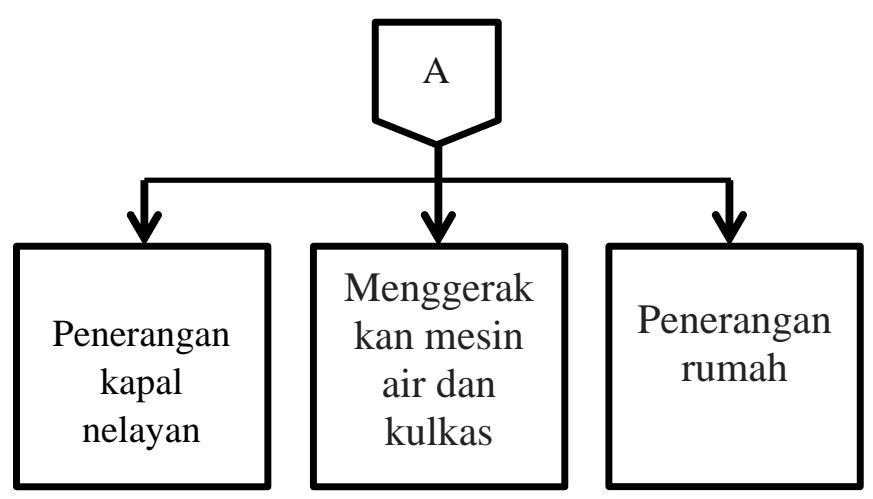

Gambar 2. Diagram alir perancangan pembangkit listrik tanpa bbm

c. Tahapan III (pengujian pembangkit listrik tanpa bbm).

Di hari kedua PkM DPRM (3 Agustus 2020), dilakukan pengujian secara simbolis untuk mendukung prosesi serah terima alat dari tim PkM DPRM kepada pihak mitra.

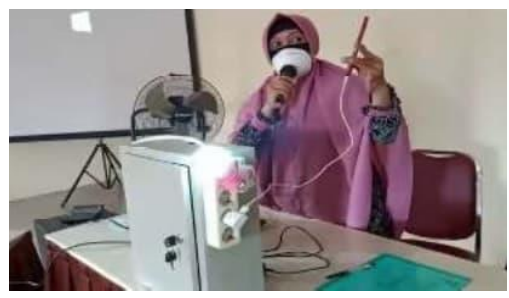

Gambar 3. Pengujian alat

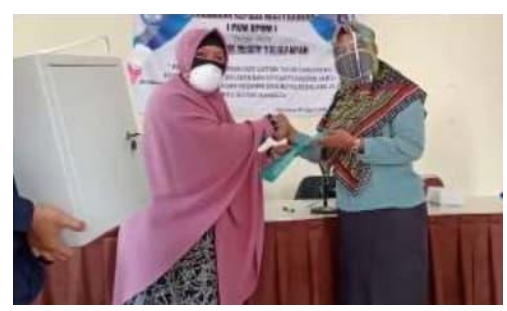

Gambar 4. Proses serah terima alat

d. Tahapan IV (Analisa dan pembahasan). Pada hari ketiga (4 Agustus 2020), kegiatan PkM dilakukan secara daring. Setiap peserta PkM dan tim PkM dibekali kuota internet sesuai keperluan daring. Kegiatan inti pada berupa diskusi internal antara peserta dan tim
PkM terkait hasil pengujian alat di rumah masing-masing. Berdasarkan kuisioner online (https://forms.gle/D8sw3LXYqH1Hxy1H6), alat tersebut sangat bermanfaat, setidaknya mengurangi pemakaian listrik PLN mereka terutama menekan biaya pembelian solar khususnya untuk penerangan kapal nelayan.

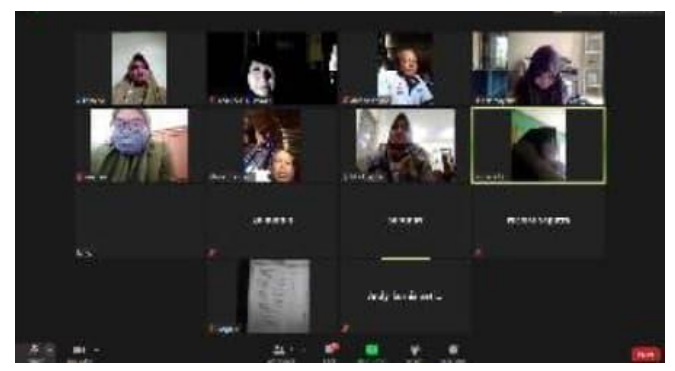

Gambar 5. Daring PkM di hari ketiga

e. Tahapan V (Kesimpulan)

Tim PkM DPRM telah berhasil sharing ilmu pengetahuan dan teknologi pembangkit listrik tanpa bbm kepada mitra Kelurahan Manggar selama 3 hari kerja. Hasilnya yaitu warga nelayan dan pedagang gorengan mampu mengimplementasikan pembangkit listrik tanpa bbm tersebut dalam kehidupan sehari-hari, terutama untuk penerangan kapal nelayan, dan keperluan lainnya.

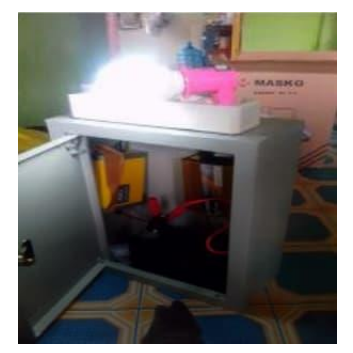

Gambar 6. Implementasi pembangkit listrik tanpa bbm oleh pedagang gorengan

\section{HASIL DAN PEMBAHASAN}

\section{Pelaksanaan kegiatan PkM}

Kegiatan PkM DPRM 2020 ini dilaksanakan selama 3 hari, yaitu tanggal 30 Juli 2020, 3 Agustus 2020 dan Teknologi Tepat Guna 
4 Agustus 2020, dengan jumlah peserta 20 orang yang terdiri dari (11 nelayan, 3 ibu rumah tangga, 4 wiraswasta, dan 2 orang karyawan Kelurahan Manggar). Adapun rundown kegiatan PkM DPRM yang dilaksanakan selama 3 hari kerja, yakni :

1) Hari Pertama (30 Juli 2020), kegiatan PkM DPRM dilaksanakan secara luring / tatap muka langsung antara tim PkM dengan mitra. Sambutan dari ketua pelaksana PkM DPRM (Andi Sri Irtawaty, S.T., M.Eng.), sambutan dari institusi Politeknik Negeri Balikpapan (Subur Mulyanto, S.T., M.T.) dan sambutan dari Lurah Manggar yang diwakili oleh Kasi Pemberdayaan Masyarakat (Linda Anggraini, S.Kom.) sekaligus membuka secara resmi acara kegiatan PkM DPRM tersebut.

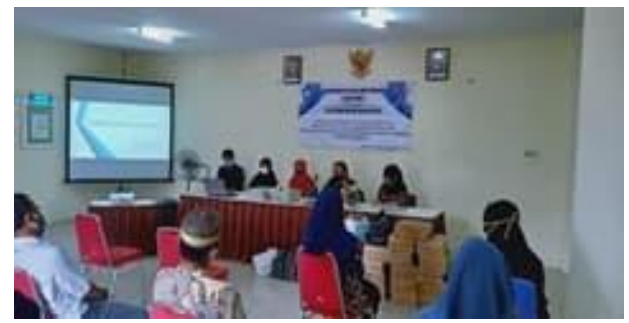

Gambar 7. Pembukaan kegiatan PkM

Dilanjutkan dengan praktek perakitan pembangkit listrik tanpa bbm, dipandu oleh narasumber dan dibantu oleh 6 asisten pendamping (Lutfie, Yoga, Rio, Andy, Abizal, dan Nicolas).

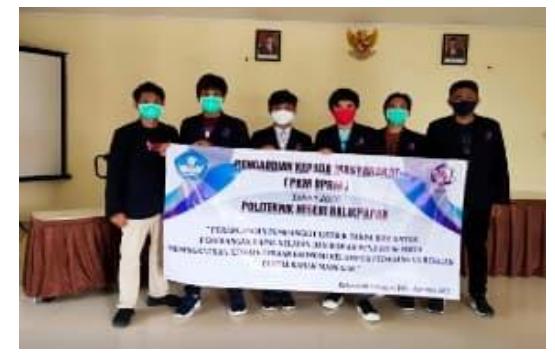

Gambar 8. Tim asisten Pendamping PkM

Perangkat utama berupa aki 12 volt 5 Ah untuk inverter kapasitas output 300 watt dan aki 12 volt 8 Ah untuk inverter kapasitas output 1000 watt.

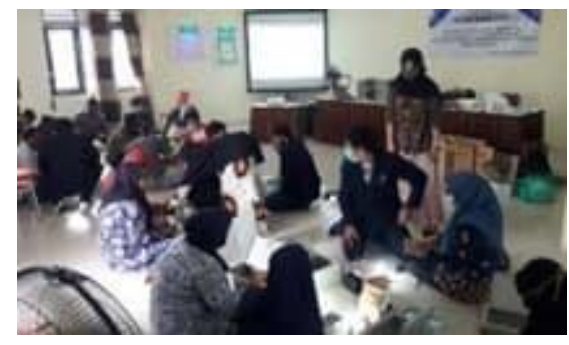

Gambar 9. Praktek perakitan pembangkit listrik tanpa bbm

2) Hari kedua ( 3 Agustus 2020 ), kegiatan PkM dilanjutkan dengan proses pengujian secara simbolis sekaligus penandatangan serah terima alat antara ketua PkM dan Lurah Manggar dalam format berita acara yang disaksikan oleh seluruh peserta PkM. Total jumlah alat yang diserahkan sebanyak 20 unit ( 19 unit berkapasitas 300 watt dan 1 unit berkapasitas 1000 watt ).

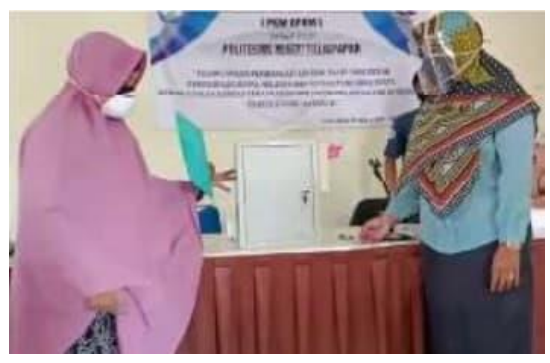

Gambar 10. Serah terima alat

3) Hari ketiga ( 4 Agustus 2020 ), kegiatan PkM berlangsung secara daring.

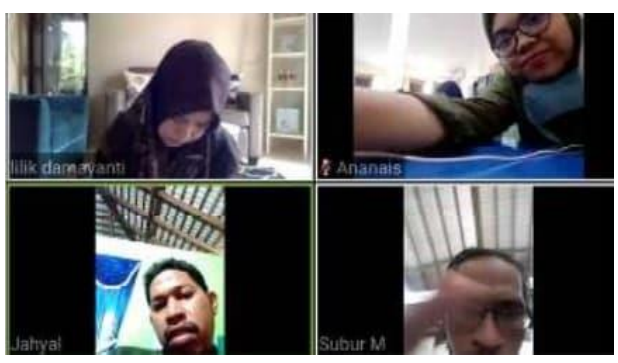

Gambar 11. Daring PkM di hari ketiga 


\section{Dampak Ekonomi dan Sosial}

Berdasarkan hasil pengisian kuisioner dari peserta PkM DPRM 2020, terlihat outcome yang sangat nyata dirasakan oleh mitra terutama yang berprofesi sebagai nelayan dan pedagang gorengan terkait manfaat dari alat pembangkit listrik tanpa BBM, yakni :

1) Untuk penerangan kapal nelayan, tidak lagi menggunakan genset, sehingga biaya operasional genset yang semula 180 liter / bulan (seharga Rp 108.000,- ),menjadi Rp 0,setelah menggunakan alat tersebut.

2) Untuk pedagang gorengan yang berjualan di malam hari, sumber penerangan mereka tidak lagi menarik sumber listrik PLN dari rumah warga sekitarnya. Sehingga penerangan di malam hari dapat terpenuhi dengan implementasi alat tersebut. Bahkan sambil berjualan gorengan, mereka dapat mengcharge hp saat baterainya drop. Berarti penghematan biaya listrik dari $\mathrm{Rp} 70.000$,/bulan menjadi Rp 0,-. Nilai ekonomis dari pembangkit listrik tanpa bbm disajikan pada tabel 1 .

Tabel 1. Perbandingan nilai ekonomis pembangkit listrik tanpa bbm dengan genset solar.

\begin{tabular}{|c|c|c|c|}
\hline No. & Profesi mitra & Sebelum & Sesudah \\
\hline 1 & Nelayan & Rp 108.000,-- & Rp 0,- \\
\hline 2 & $\begin{array}{c}\text { Pedagang } \\
\text { gorengan }\end{array}$ & Rp 70.000,- & Rp 0,- \\
\hline
\end{tabular}

Jika ditampilkan dalam bentuk grafik seperti pada gambar 12 .

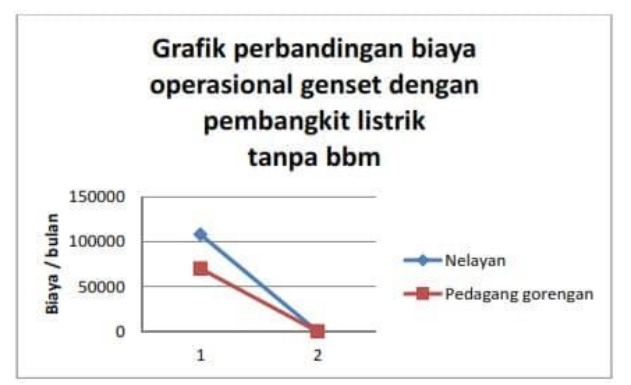

Gambar 12. Grafik perbandingan biaya operasional pembangkit listrik tanpa bbm dengan genset solar.

\section{Kontribusi Mitra terhadap Pelaksanaan}

Mitra berkontribusi menyediakan fasilitas sarana gedung aula Kelurahan manggar untuk kegiatan PkM tersebut.

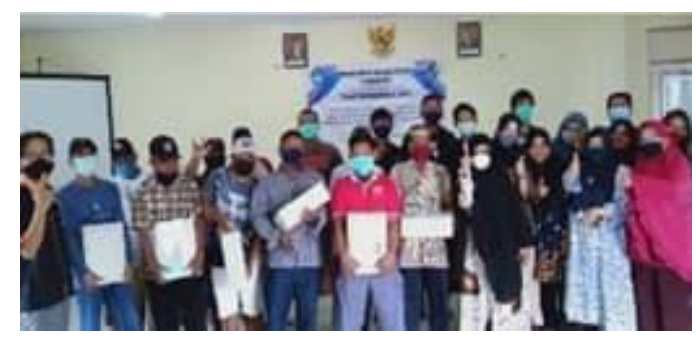

Gambar 13. Tim PkM dan mitra

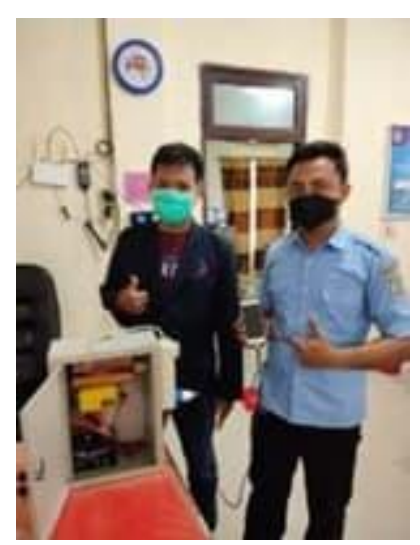

Gambar 14. Implementasi pembangkit listrik tanpa bbm di Kelurahan manggar

\section{KESIMPULAN}

Kegiatan PkM DPRM berlangsung selama 3 hari kerja dan berjalan dengan sukses. Berkat kerjasama yang sangat baik antara tim penyelenggara dengan pihak mitra Kelurahan Manggar. Rasa antusias warga nelayan dan pedagang gorengan dalam mengikuti kegiatan tersebut. Terlihat nyata. Mereka langsung mengimplementasikan alat tersebut dalam aktivitas mereka sehari-hari. Kegiatan PkM DPRM secara luring diakhiri dengan penandatangan berita acara serah terima alat antara tim PkM DPRM dengan pihak mitra yang diwakili oleh Lurah Manggar. Terdapat 20 alat yang diserahkan yakni 19 unit alat berkapasitas 300 watt dan 1 unit alat berkapasitas 1000 watt, diserahkan pada tanggal

$$
\text { Teknologi Tepat Guna }
$$


3 Agustus 2020, disaksikan oleh seluruh peserta PkM DPRM.

\section{UCAPAN TERIMAKASIH}

Ucapan terimakasih disampaikan kepada unit P3M Poltekba, Kelurahan Manggar dan seluruh tim PkM yang terlibat dalam kegiatan PkM, terutama kepada yang penghargaan setinggitingginya kepada Kementerian Pendidikan dan Kebudayaan atas tercapainya seluruh output dari kegiatan PkM DPRM ini. Semoga inovasi dan kreatifitas teknologi tepat guna lainnya dapat dikembangkan pada tahun berikutnya.

\section{REFERENSI}

Arota, A. S. (2013). Perancangan Sistem Pembangkit Listrik Hibrida (Energi Angin Dan Matahari) Menggunakan Hybrid Optimization Model For Electric. Jurnal MIPA Unstrat, 2(2), 145-150.

Hutagulung, S. N. (2017). PROTYPE RANGKAIAN INVERTER DC KE AC 900 WATT. Jurnal Pelita Informatika, 16(3), 278-280.
Juwito, A. F. (2012, Mei). Optimalisasi Energi Terbarukan pada Pembangkit Tenaga Listrik dalam Menghadapi Desa Mandiri Energi di Margajaya. Jurnal Ilmiah Semesta Teknika, 15(1), 22-34.

Mundus, R. (2010). RANCANG BANGUN INVERTER DENGAN MENGGUNAKAN SUMBER BATERAI DC12V.

Sinaga, Y. A. (2016). Rancang bangun inv dengan kontrolerter 1 phasa dengan kontrol pembangkit pulsa width modulation.

Wardhana, I. S. (2006). Perancangan inverter push pull resonan paralel pada aplikasi fotovoltaik.

Yani, A. (2018). RANCANG BANGUN PROTOTYPE PEMBANGKIT LISTRIK TENAGA UAP MINI SEBAGAI MEDIA PRAKTIKUM MAHASISWA . Jurnal Teknik Mesin Univ. Muhammadiyah Metro, 7(2). 